\title{
棉花叶片光合作用的光抑制和光 呼吸的关系*
}

\author{
郭连旺 许大全 沈允钢 \\ (中国科学院上海植物生理研究所, 上海 200032)
}

\section{关键词 光抑制 光呼吸 缓解作用 磷限制}

光呼吸在光下释放 $\mathrm{CO}_{2}$, 与固定 $\mathrm{CO}_{2}$ 的光合作用同时进行, 是早已为人们所熟悉的事 实, 但其生理意义迄今仍不十分清楚. 已有研究表明, 在没有 $\mathrm{CO}_{2}$ 的条件下, 抑制了光呼吸以 后强光下叶片或叶绿体出现明显的光抑制, 而其它条件不变, 供给浓度接近 $\mathrm{CO}_{2}$ 补偿点的 $\mathrm{CO}_{2}$ 时, 这种光抑制即可消除, 因此推测在 $\mathrm{CO}_{2}$ 浓度为零或低于 $\mathrm{CO}_{2}$ 补偿点的强光条件下光呼吸 对光合机构有保护作用门. 但是, 在普通空气条件下是否如此, 还未见研究报道, 我们曾观察 到, 晴天中午强太阳光下, 伴随光合作用的光抑制, 田间棉花叶片的光呼吸增强 [2]. 那么, 在这种 普通空气条件下, 光呼吸是否有缓解光抑制的作用呢? 我们通过观测叶片的气体交换、叶绿 素苂光和无机磷含量, 对这个问题进行了研究.

\section{1 材料和方法}

\section{1 实验材料}

实验以田间生长的盆栽棉花 (Gossypium hirsutum) 为材料, 在开花前期施加 1 次豆饼肥, 在开花的中期和后期各施 1 次复合化肥, 除雨天外每日浇水. 开花结铃期完全展开的叶片用 于各项测定.

\section{2 低氧条件下强光处理}

用 $\mathrm{N}_{2}, \mathrm{CO}_{2}$ 和空气配制含 $2.1 \% \mathrm{O}_{2}$ 和 $330 \sim 340 \mu \mathrm{L} \cdot \mathrm{L}^{-1}$ 的 $\mathrm{CO}_{2}$ 的低氧气体. 用两个形 状和大小相同的叶室夹住同一叶片对称的两半, 一个叶室通以低氧气体, 另一叶室通以普 通空气, 同时置于碘铇灯下照光. 照光条件与田间条件下的中午强光 (1500 1 $700 \mu \mathrm{mol}$ 光 量子 $\cdot \mathrm{m}^{-2} \cdot \mathrm{s}^{-1}$ ) 类似, 方法同文献[2].

\section{3 气体交换测定}

净光合速率 $\left(\mathrm{Pn}, \mu \mathrm{mol} \mathrm{CO} \cdot \mathrm{m}^{-2} \cdot \mathrm{s}^{-1}\right)$ 、表观量子效率 $(\mathrm{AQY})$ 及光量子通量密度 $(\mathrm{PFD}$, $\mu \mathrm{mol}$ 光量子 $\left.\cdot \mathrm{m}^{-2} \cdot \mathrm{s}^{-1}\right)$ 和气温 $\left(\mathrm{Ta},{ }^{\circ} \mathrm{C}\right)$ 等指标均用美国 $\mathrm{CID}$ 公司生产的 $\mathrm{CI}-301$ 型 $\mathrm{CO}_{2}$ 气 体分析系统测定, 测定方法及光呼吸速率 $\left(\mathrm{Pr}, \mu \mathrm{mol} \mathrm{CO}_{2} \cdot \mathrm{m}^{-2} \cdot \mathrm{s}^{-1}\right)$ 的计算同文献[2].

\section{4 荧光参数的测定}

用美国 Morgan CF-1000 便携式荧光仪测定叶片的 PSII 光化学效率 $\left(F_{\mathrm{v}} / F_{\mathrm{m}}\right)$ 和初始苂光

1995-01-05 收稿, 1995-05-12 收修改稿

*国家自然科学重点基金资助项目 
( $F_{0}$ ，相对单位), 方法同文献[2]

\section{5 无机磷 $(\mathbf{P i})$ 的引入}

将叶片剪下后, 于水面下再剪去一段叶柄, 然后移人浓度为 $10 \mathrm{mmol} / \mathrm{L}$ 的 $\mathrm{KH}_{2} \mathrm{PO}_{4}$ 溶液 中, 在 $700 \sim 800 \mu \mathrm{mol}$ 光量子 $\cdot \mathrm{m}^{-2} \cdot \mathrm{s}^{-1}$ 的光强下照光 $1 \mathrm{~h}$.

\section{6 叶片 $\mathrm{Pi}$ 含惧的测定}

用液氮固定叶片, 将冷冻叶片用匀浆器在含三氯乙酸的 STN 缓冲液 $(0.4 \mathrm{~mol} / \mathrm{L}$ 的 Sucrose, $50 \mathrm{mmol} / \mathrm{L}$ 的 Tris, $10 \mathrm{mmol} / \mathrm{L}$ 的 $\mathrm{NaCl}, \mathrm{pH} \mathrm{7.8)}$ 中研磨成浆, 以 $1500 \times \mathrm{g}$ 离心 $2 \mathrm{~min}$, 取其上 清液再以 $7000 \times g$ 离心 $2 \mathrm{~min}$, 取 $0.5 \mathrm{~mL}$ 上清液用钼酸铵试剂显色, 在 $660 \mathrm{~nm}$ 测 $\mathrm{OD}$ 值.

\section{2 结果}

\section{1 低氧条件下棉花叶片光合作用的光抑制}

一张叶片的左右两部分分別通以低氧气体和普通空气, 在照射相同强度的光照 (1500 $1700 \mu \mathrm{mol}$ 光量子 $\left.\cdot \mathrm{m}^{-2} \cdot \mathrm{s}^{-1}\right) 3 \mathrm{~h}$ 以后, 低氧条件下的叶片部分 $F_{\mathrm{V}} / F_{\mathrm{m}}$ 下降幅度比普通空气下 的部分大得多,而且不易恢复 (图 1)。7次测定结果表明 (数据未全部列出)，低氧条件下照射 $3 \mathrm{~h}$ 强光使叶片 $F_{\mathrm{v}} / F_{\mathrm{m}}$ 平均下降 $33 \%$, 而在普通空气中同样的强光处理使 $F_{\mathrm{v}} / F_{\mathrm{m}}$ 平均降低仅 $14 \%$. 气体交换测定的结果 (图 2)也表明,照射强光 $3 \mathrm{~h}$ 后,同一叶片低氧条件下的部分与普 通空气中的部分相比, AQY(以光强曲线的初始斜率表示)下降幅度明显增大。这些结果表 明, 在低氧抑制了光呼吸以后, 叶片光合作用的光抑制明显加剧.

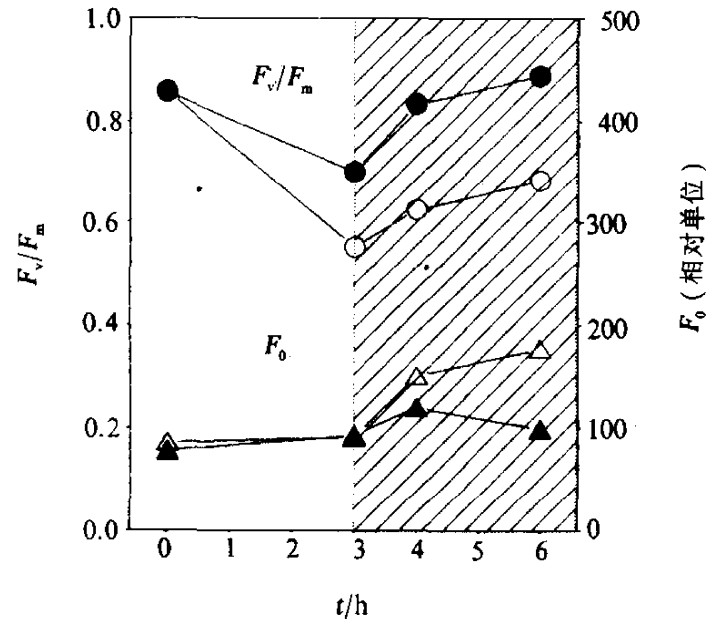

图 1 两种气体条件下照射 $3 \mathrm{~h}$ 强光后叶片苂光 参数的变化

$\Delta$, 一示普通空气中的对照， $\Delta, 0$ 示低氧气体下的处理。 每个点都是 3 5个数据的平均值. 阴影部分表示照过强 光的叶片在弱光 (低于 $50 \mu \mathrm{mol}$ 光量子 $\cdot \mathrm{m}^{-2} \cdot \mathrm{s}^{-1}$ ) 下的恢

复. 7 次实验结果类似,仅列出 1 次. 空气温度 $26^{\circ} \mathrm{C}$

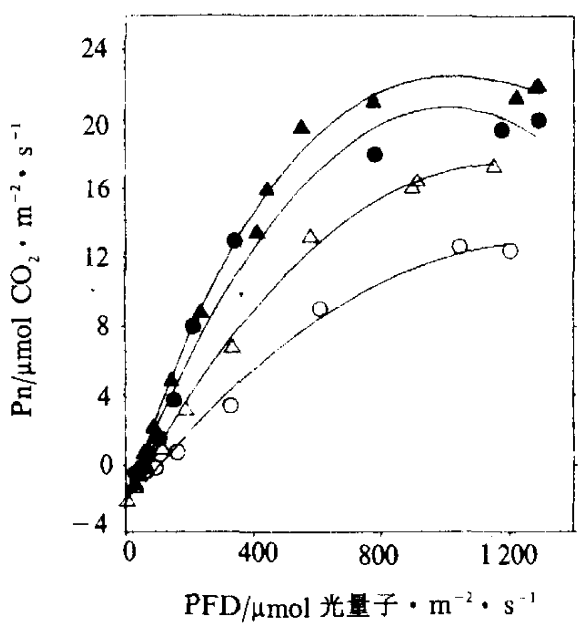

图 2 两种气体条件下照射 $3 \mathrm{~h}$ 强光后叶片光令 量子效率的变化

ム示普通空气中的强光处理前, $\triangle$ 示普通空气中的强光 处理后, 一示低氧气体中的强光处理前, ○示低氧气体中 的强光处理后. 图中数据均在低氧气体下测得. 空气 温度 $24^{\circ} \mathrm{C}$

\section{2 低篟和强光条件下叶片净光合速率的下降}

图 3 的结果表明, 强光照射过程中, 供给普通空气的叶片光饱和的光合速率略有降低, 而 
低氧气体中叶片的同一参数却大幅度下降, 说明低氧条件虽然抑制了光呼吸, 使净光合速率 比光呼吸存在时高, 但是这样的高光合速率在低氧条件下不能持久.

\section{3 低年和强光条件下叶片无机磷含量的变化}

为了探寻低氧条件下叶片净光合速率下降的原因, 我们测定了照强光后叶片 $\mathrm{Pi}$ 含量的变 化. 多次测定结果 (表 1) 表明, 叶片在低氧条件下照光的部分与普通空气中照光的部分相 比, $\mathrm{Pi}$ 含量减少的幅度明显增大. 若给叶片喂人 $\mathrm{Pi}$, 则两部分叶片的净光合速率变化没有明 显差别 (图 4). 喂磷以后, 两部分叶片的 $F_{\mathrm{v}} / F_{\mathrm{m}}$ 在照射强光 $3 \mathrm{~h}$ 后下降幅度也相近 (资料 略)，这说明消除磷限制后低氧条件下叶片的光㧕制得到缓解.

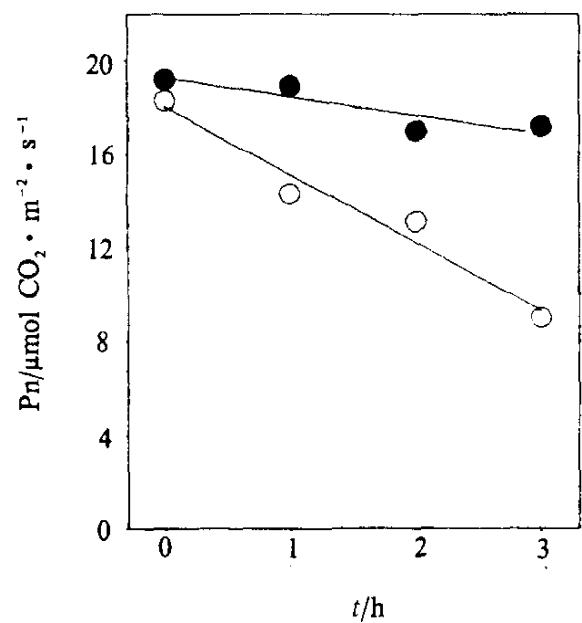

图 3 强光和两种气体条件下叶片光饱和 的光合速率的变化过程

-示普通空气, ○示低氧处理. 图中的净光合速率 在低氧及饱和光强下测定, 每个点都是 5 个以上数 据的平均值. 4 次实验结果相似, 仅列出 1 次. 空 气温度 $24^{\circ} \mathrm{C}$

表 1 两种气体条件下 $3 \mathrm{~h}$ 强光处理后叶片 $\mathrm{Pi}$ 含量 $\left(\mu \mathrm{mol} \mathrm{Pi} \cdot \mathrm{cm}^{-2}\right)$ 的变化 ${ }^{\mathrm{a})}$

\begin{tabular}{clcc}
\hline 实验 & & \multicolumn{1}{c}{1} & \multicolumn{1}{c}{2} \\
\hline \multirow{3}{*}{ 普通空气 } & 照强光前 & 0.227 & 0.226 \\
& 照强光后 & 0.199 & 0.172 \\
& 降低 $/ \%$ & -12.3 & -23.9 \\
\hline \multirow{3}{*}{ 低氧气体 } & 照强光前 & 0.243 & 0.240 \\
& 照强光后 & 0.149 & 0.131 \\
& 降低 $/ \%$ & -38.7 & -45.4 \\
\hline
\end{tabular}

a) 先后做 5 次实验,结果类似,表中仅列出 2 次的结果

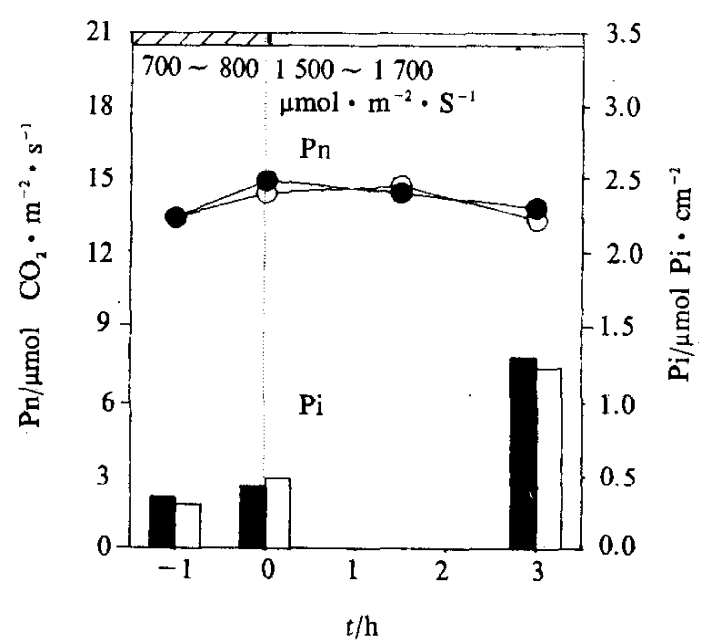

图 4 喂人 $\mathrm{Pi}$ 以后两种气体条件下叶片光饱和的 光合速率的变化

图中的光合速率在低氧及饱和光强下测得, 每个点都是 5 个以上数据的平均值. - 示普通空气中的对照, ○示低氧 气体下的处理. $0 \mathrm{~h}$ 之前表示预先饲喂 Pi 的过程. 空气温 度 $23^{\circ} \mathrm{C}$

\section{3 讨论和结论}

光抑制的本质是光合机构吸收的过剩 光能引起光合功能的降低 ${ }^{[3]}$. 因此, 过剩光 能越多, 光抑制越严重. 光呼吸长期以来被 认为是一种与光合作用相伴发生的 “无效” 耗能过程,一些学者曾作出大量的努力试图 通过抑制光呼吸来提高光合作用和作物产 量, 但均告失败. 然而, 光呼吸的耗能作用 可能会减少光合机构的光能过剩, 因而可能 对光抑制有缓解作用 ${ }^{[1]}$. 可是, 这个推测是以强光和无 $\mathrm{CO}_{2}$ 条件下的实验结果为依据作出 的. 至于普通空气条件下这个推测是否成立, 尚末见验证.

我们这里报道的结果证实, 在普通空气的 $\mathrm{CO}_{2}$ 浓度下, 低氧抑制光呼吸引起了光抑制的 
加剧 (图 1,2), 表明在普通空气中光呼吸的存在会减轻光抑制. 但是, 这种缓解作用的原因 显然不同于 Osmond 所述 ${ }^{[1]}$, 即光呼吸途径是以 $\mathrm{O}_{2}$ 替代了 $\mathrm{CO}_{2}$ 作电子传递最终受体的光合耗 能过程，因为这不是无 $\mathrm{CO}_{2}$ 的条件. 而且,在解释低氧条件下光抑制的加剧时, 也不能简单地 认为低氧消除了光呼吸这一耗能过程从而引起了过剩光能的增加, 因为低氧条件下虽然光呼 吸受到抑制, 但光合速率却会因减少 $\mathrm{O}_{2}$ 与 $\mathrm{CO}_{2}$ 的竞争而增加, 增加的部分正是普通空气条件 下光呼吸使光合减少的部分. 因此, 在低氧条件下不会因光呼吸的消除而减少光能的消耗. 考虑到 Sharkey 等 ${ }^{[4]}$ 的光合作用受 Pi 限制的假说和 Gao 等 ${ }^{[S]}$ 关于光呼吸的运转有补充叶绿 体光合作用所需的 $\mathrm{Pi}$ 的功能的观点, 对光呼吸减轻光抑制的原因的一个可能的解释, 是光呼 吸能够促进碳代谢过程中 Pi 的循环利用.

我们对叶片 $\mathrm{Pi}$ 含量测定和喂 $\mathrm{Pi}$ 实验的结果证实了上述猜想. 在强光下, 当用低氧抑制 了光呼吸以后, 虽然光合速率一开始就提高了, 但随着时间的延长, 低氧条件下叶片的净光合 速率比普通空气中的叶片降低快得多 (图 3). 与此同时我们观察到 $3 \mathrm{~h}$ 强光后叶片内的 $\mathrm{Pi}$ 含 量在低氧条件下比普通空气中下降幅度大得多 (表 1), 而通过喂 Pi 消除 Pi 限制后, 两种气体 条件下净光合速率变化进程的差别消失 (图 4), 这表明低氧强光条件下 Pi 的不足造成了光合 速率较快的降低. 这可能是由于低氧条件下光合速率提高, 叶绿体中的 Pi 通过光合作用很快 转化成有机磷形式的光合产物 (如磷酸丙糖), 造成 Pi 的含量迅速下降。在这种情况下, 一方 面光合产物的大量累积可能对光合作用产生反馈抑制, 另一方面 Pi 不足会通过限制 ATP 合 成等多种方式限制光合速率 ${ }^{[4]}$. 然而叶片在普通空气中照强光时, 光呼吸过程中产生的磷酸 乙醇酸在叶绿体中转化成乙醇酸, 并释放出 $\mathrm{Pi}, \mathrm{Pi}$ 重新参与碳代谢, 这就缓解了 $\mathrm{Pi}$ 供求不 平衡的矛盾.

看来, 在普通空气下照强光时, 光呼吸可能通过两种途径缓解了叶片光合作用的光抑制:

1) 消耗光合机构吸收的过剩光能；2）促进 Pi 的循环利用, 缓解 Pi 不足对光合作用的限 制, 从而间接地减少或消除潜在的过剩光能的产生. 因此, 我们认为, 光呼吸可能是自然条件 下植物光合机构避免强光破坏的一种重要机制, 尤其是在叶片遭受强光或磷缺乏等环境胁 迫的条件下.

我们曾观察到, 在棉花盛花期后, 给叶片喷施磷酸盐可以提高叶片的光合速率. 可见, 在 棉花生长的后期, 随着蕾铃的大量出现, 叶片光合作用容易受到 Pi 的限制, 尽管这时从植株外 观上看不到缺 Pi 症状．在这种情况下, 追施磷肥可能会有利于增加棉花产量.

\section{参 考文 献}

1 Osmond C B. Photorespiration and photoinhibition. some implications for energetics of photosynthesis. Biochim Biophys Acta, 1981, 639(2): $77 \sim 98$

2 郭连旺, 许大全, 沈允钢. 田间棉花叶片光合效率中午降低的原因. 植物生理学报, 1994, (4): 360 366

3 Long S P, Humphries S, Falkowski P G. Photoinhibition of photosynthesis in nature. Ann Rev Plant Physiol Plant Mol Biol, 1994, 45:633 662

4 Sharkey T D, Stitt M, Heineke D et al. Limitation of photosynthesis by carbon metabolism. II. $\mathrm{O}_{2}$-insensitive $\mathrm{CO}_{2}$ uptake results from limitation of triose phosphate utilization. Plant Physiol, 1986, 81:1 123 1129

5 Gao S J, Chen S S, Li M Q. Effects of phosphorus nutrition on photosynthesis and photorespiration in tobacco leaves. Acta Phytophysiology Sinica, 1989, 15(3):281 287 